\title{
Effect of CD133/prominin-1 antisense oligodeoxynucleotide on in vitro growth characteristics of Huh-7 human hepatocarcinoma cells and U251 human glioma cells
}

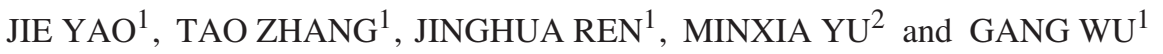 \\ ${ }^{1}$ Cancer Center, Union Hospital, ${ }^{2}$ Department of Immunology, Tongji Medical College, Huazhong University \\ of Sciences and Technology, Wuhan 430023, Hubei Province, P.R. China
}

Received June 1, 2009; Accepted July 10, 2009

DOI: $10.3892 /$ or_00000500

\begin{abstract}
The stem cell marker CD133/prominin-1, is a pentaspan membrane glycoprotein, which has also been identified as a cancer stem cell (CSC) marker in several solid tumor types, including those of the prostate, liver, colon and brain. The function of CD133 in these tumors is still unknown. We hypothesize that the function of CD133 is correlated with the characteristics of the $\mathrm{CD} 133^{+} \mathrm{CSC}$ and may affect the growth of the tumor cell population as a whole. In this study we used antisense oligodeoxynucleotides (ASODNs) of CD133 to knock-down (KD) CD133 expression. We showed that the CD133-KD inhibited proliferation of U251 human glioma cells, decreased the colony forming ability and altered the cell cycle distribution in Huh-7 human hepatocellular carcinoma cells. Our data suggest that CD133 may play an important functional role in the growth of these tumor cells. Moreover, this study also showed that prominin-2, another protein in the same family as CD133/prominin-1, may not have a similar function.
\end{abstract}

\section{Introduction}

Increasing evidence shows that cancers contain a small population of cells with 'stem-like' characteristics termed cancer stem cells (CSCs). They have a long lifespan, high self-renewal capacity, multilineage differentiation ability, and unlimited proliferative potential which enables them to maintain and expand the cancer cell population, while they often stay in a quiescent stage $(\mathrm{G} 0 / \mathrm{G} 1)(1,2)$ resistant to chemotherapy or radiation therapy $(3,4)$. Current treatments that act against the bulk of the cancer but do not target the CSCs are unlikely to result in long-term remissions (5).

Correspondence to: Dr Tao Zhang, Cancer Center, Union Hospital, Huazhong University of Sciences and Technology, 1277 Jiefang Ave, Wuhan 430022, Hubei Province, P.R. China

E-mail: taozhangwh@yahoo.com.cn

Key words: cancer stem cells, CD133/prominin-1, glioma, hepatocellular carcinoma, antisense oligonucleotides
Treatments targeting specific functional proteins that directly affect the characteristics of CSCs may be a more promising way to cure cancers.

CD133/prominin-1, a cell surface marker of somatic and embryonic stem/progenitor cells (6), is the first identified member of the prominin family of pentaspan membrane glycoproteins. The specific functions and ligands of the prominins are still unclear (7-9). Recent research shows that CD133 is also a cancer stem cell marker in many types of solid tumors, including those of prostate, liver, colon and brain (10-16); but the functional role of CD133/prominin-1 in these tumors is unknown.

Some reports have shown that CD133/prominin-1 is expressed in embryonic stem cells (ESCs) and ESC-derived progenitors but not in differentiated cells. CD133/prominin-1 transcript and protein levels are down-regulated after differentiation (6). Moreover, in the intestine-derived epithelial cell line Caco-2, researchers found that CD133/prominin-1 expression was also down-regulated upon differentiation, meanwhile, some membrane particles containing CD133/ prominin-1 were excluded from Caco- 2 cells during this procedure (17).

We hypothesize that CD133/prominin-1 may have a function correlated with the 'stem-like' characteristics of stem/progenitor cells, including CSCs. Because of the critical role of CSCs in maintaining the tumor cell population, the tumor growth may be affected by modulating the expression of CD133/prominin-1 protein.

Herein we report that knock-down of CD133 expression by using CD133/prominin-1 antisense oligodeoxynucleotides (ASODNs) inhibits proliferation of U251 human glioma cells (low CD133 expression), and decreases colony formation and alters cell cycle distribution in Huh-7 human hepatocellular carcinoma cells (high CD133 expression). It is suggested that CD133 may play a functional role in the growth of these tumor cells, possibly by affecting the CD133+ CSCs. In addition, this study also shows that another protein in the prominin family, prominin-2, does not have the same function.

\section{Materials and methods}

Cell lines and culture conditions. Huh-7 cells, a human hepatocellular carcinoma cell line, and U251 cells, a human 
glioma cell line, were obtained from the XiangYa Medical University (Hunan, China), and cultured in RPMI-1640 medium (Gibco, BRL, Grand Island, NY, USA) containing $1 \%$ penicillin and streptomycin (Gibco), $12.5 \mathrm{mM}$ HEPES buffer (Sigma, St. Louis, MO, USA), and supplemented with $10 \%$ heat-inactivated fetal bovine serum (Sigma).

\section{Oligodeoxynucleotides (ODN) transfection}

Phosphorothioate ODN sequences. Non-sense (NS)-ODN sequence: 5'-GAG GAG AGC GAG GCC CGT-3' (18); two independent CD133/prominin-1 antisense (AS)-ODN sequences: sequence 1, 5'-AAG AGA ATG CCA ATG GGT C-3'; sequence 2, 5'-ATA GCT AGC AAG ATC CTC C-3'; two independent prominin-2 ASODN sequences: sequence 1, 5'-AAG GAA CTT GCA GTC TGT G-3'; sequence 2, 5'-GAA AGG ATT GAG CTG CAC C-3'. All the ODN sequences utilized were synthesized by Sangon Biotechnology Co., Ltd. (Shanghai, China).

Groups. To investigate whether the function of CD133/ prominin-1 can affect the in vitro growth characteristics of Huh-7 cells, and whether prominin-2 has a similar or synergistic function, the Huh-7 cells were divided into five groups: a control group, $1.5 \mu \mathrm{g} /$ well NSODN group, $1.5 \mu \mathrm{g} /$ well prominin-1 ASODN group, $1.5 \mu \mathrm{g} /$ well prominin-2 group, $0.75 \mu \mathrm{g} /$ well prominin-1 ASDON $+0.75 \mu \mathrm{g} /$ well prominin-2 ASODN group. In another transfection experiment, Huh-7 cells and U251 cells were each divided into three groups: control group, $1.5 \mu \mathrm{g} / \mathrm{well}$ NSODN group and $1.5 \mu \mathrm{g} / \mathrm{well}$ prominin-1 ASODN group), to identify the functional role of CD133/prominin-1 in the in vitro growth of these two types of tumor cells.

Transfection protocol. The transfection condition was determined according to the manufacturer's instructions (Dojindo, Kumamoto, Japan), to optimize the transfection efficiency. One day before transfection, the cells were collected, resuspended in $0.5 \mathrm{ml}$ of culture medium, seeded into 24-well plates, and incubated at $37^{\circ} \mathrm{C}$. The concentration of the cells was adjusted to yield $40-60 \%$ confluency per well (0.6$0.9 \times 10^{5}$ cells). After $24 \mathrm{~h}, 30 \mu \mathrm{l}$ of serum-free medium, $1.5 \mu \mathrm{g}$ of ODN, and $6 \mu \mathrm{l}$ of Hilymax transfection reagent (all for each well) were mixed by gentle pipetting in a sterile tube and incubated at room temperature for $15 \mathrm{~min}$ to allow ODNHilymax complex formation. The ODN-Hilymax complex was then added into each well of the 24 -well plates prepared before. The plates were incubated at $37^{\circ} \mathrm{C}$ in a $\mathrm{CO}_{2}$ incubator and $4 \mathrm{~h}$ after transfection, the medium in the plates was changed. At $36 \mathrm{~h}$ after transfection, CD133 mRNA level and protein expression were measured.

cDNA production and relative quantitative PCR. Total RNA was extracted using an RNA kit (Qiagen, Hilden, Germany) and cDNA was synthesized from $1 \mu \mathrm{g}$ of total RNA, with an oligo(dT) primer and Moloney murine leukemia virus (M-MLV) reverse transcriptase (Gibco, BRL) according to the manufacturer's instructions. The cDNA samples were subjected to PCR amplification with specific primers. Primers were synthesized by Sangon Biotechnology Co., Ltd. (Shanghai, China). PCR was performed under linear conditions in order to reflect the original amount of the specific transcripts. CD133 primers were (sense, 5'-CACTCTATACCAA AGCGTCAA-3'; antisense, 5'-CACGATGCCACTTTCT CAC-3'). PCR program for CD133: $94^{\circ} \mathrm{C}$ for $3 \mathrm{~min}$, followed by 35 cycles of denaturation at $94^{\circ} \mathrm{C}$ for $30 \mathrm{sec}$, annealing at $53^{\circ} \mathrm{C}$ for $55 \mathrm{sec}$, elongation at $72^{\circ} \mathrm{C}$ for $60 \mathrm{sec}$, followed at the end by $5 \mathrm{~min}$ elongation at $72^{\circ} \mathrm{C}$. The GAPDH housekeeping gene was used as an internal control. GAPDH primers were (sense, 5'-CATGACAACTTTGGTATCGTG-3'; antisense, 5'-GTGTCGCTGTTGAAGTCGTCAGA-3'). PCR program for GAPDH: $94^{\circ} \mathrm{C}$ for $3 \mathrm{~min}$, followed by 35 cycles of denaturation at $94^{\circ} \mathrm{C}$ for $30 \mathrm{sec}$, annealing at $55^{\circ} \mathrm{C}$ for $55 \mathrm{sec}$, elongation at $72^{\circ} \mathrm{C}$ for $60 \mathrm{sec}$, followed at the end by $5 \mathrm{~min}$ elongation at $72^{\circ} \mathrm{C}$. Amplified products $(3 \mu \mathrm{l})$ were electrophoresed on a $2 \%$ agarose gel. Pictures of the gels were taken under ultraviolet (UV) light and band intensity was expressed as relative absorbance units for analysis. The CD133 mRNA levels relative to GAPDH were calculated and analyzed by Bandscan 5.0. The experiments were performed three times.

Fluorescent cytometry analysis. The expression of CD133 surface marker was analyzed by fluorescent cytometry (FACS). Huh-7 or U251 cells were adjust to a concentration of $1 \times 10^{6}$ cells $/ \mathrm{ml}, 100 \mu \mathrm{l}$ of single-cell suspensions were incubated at $4^{\circ} \mathrm{C}$ for $30 \mathrm{~min}$ with $0.1 \mu \mathrm{g} / \mathrm{ml}$ FITC-coupled anti-CD133 antibodies (Biosynthesis, Beijing, China), analyzed with a BD FACS-Calibur (Becton-Dickinson) and CellQuest software. The experiments were performed three times.

Colony forming assays. To investigate whether the function of CD133/prominin-1 and/or prominin-2 affects the colony forming ability of Huh-7, the cells were transfected as follows: control group, $1.5 \mu \mathrm{g} / \mathrm{well} \mathrm{NSODN}$ group, $1.5 \mu \mathrm{g} / \mathrm{well}$ prominin-1 ASODN group, $1.5 \mu \mathrm{g} /$ well prominin-2 group, and $0.75 \mu \mathrm{g} /$ well prominin- $1 \mathrm{ASDON}+0.75 \mu \mathrm{g} / \mathrm{well}$ prominin-2 ASODN group. At $36 \mathrm{~h}$ after transfection, singlecell suspensions were seeded at a density of 25, 50 and 100 cells/well in 96-well plates, 10 wells for each group were prepared. After $12 \mathrm{~h}$, when all the cells had attached, the exact number of cells seeded in each well was calculated visually with an inverted microscope. Colony growth was assessed at 2 weeks. Percent colony formation $(\%)=($ total number of colonies/total number of cells seeded) $\mathrm{x} 100$. The experiments were performed three times.

To investigate whether the function of CD133/prominin-1 affects the colony forming ability of Huh-7, the cells were transfected in three groups, control, NSODN and prominin-1 ASODN. At $36 \mathrm{~h}$ after transfection, single-cell suspensions from the three Huh-7 groups were seeded at a density of 300 cells/well in 24-well plates, with 3 wells for each group prepared. Clonal growth was assessed at 2 weeks. Percent colony formation $(\%)=($ total number of colonies/total number of cells seeded) x 100 . The experiments were performed three times.

Cell proliferation assay. At $36 \mathrm{~h}$ after transfection, singlecell suspensions from three U251 groups (control, NSODN and prominin-1 ASODN) were seeded at 100 cells/well in 
A

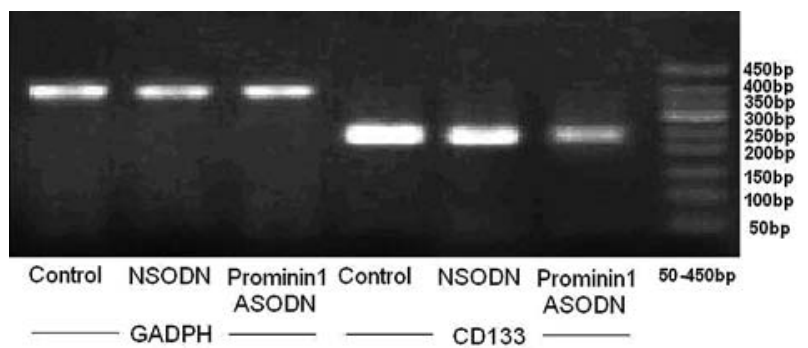

C

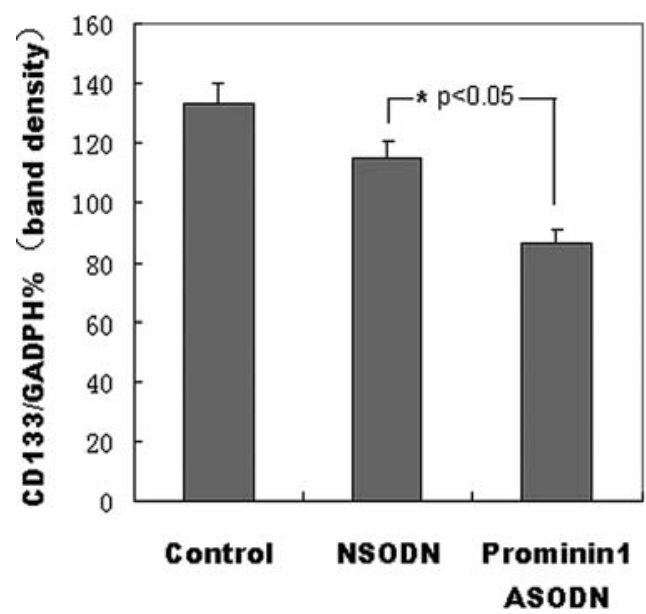

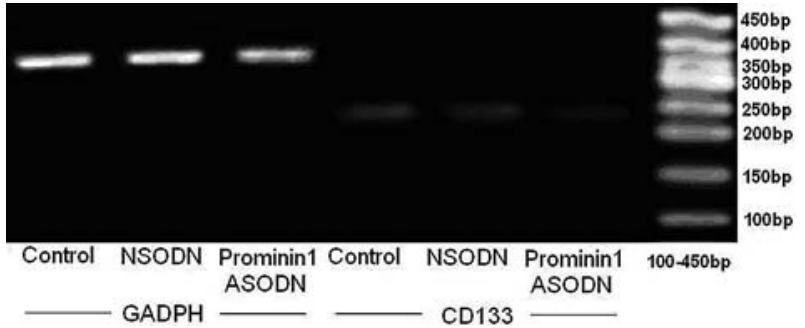

D

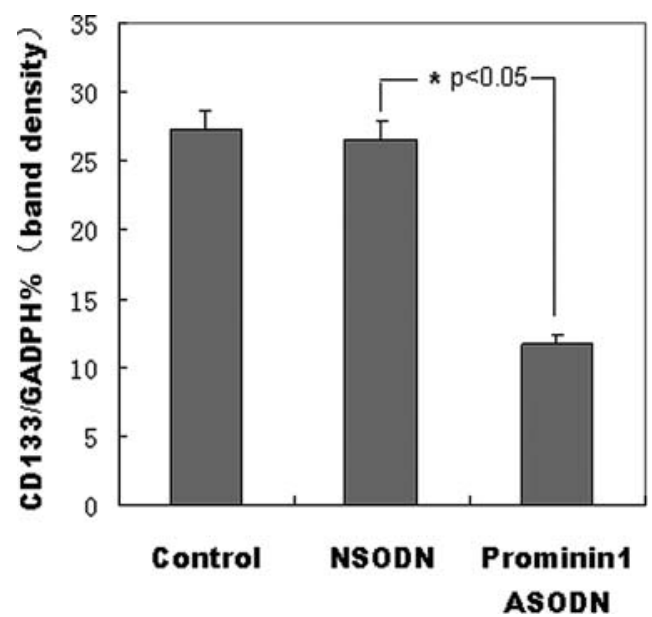

Figure 1. (A) and (B) mRNA levels of CD133/prominin-1 and the internal control GAPDH in each group of Huh-7 and U251 cells 36 h after transfection were examined by RT-PCR. (C) and (D) A densitometric scan of the RT-PCR band was performed, and the relative CD133/prominin-1 mRNA level of each group of Huh-7 and U251 cells after the transfection is shown as the percentage ratio between the band intensity of CD133/prominin-1 and GAPDH. The data are means \pm SD from three independent experiments. ${ }^{*} \mathrm{p}<0.05$ compared with NSODN group.

96-well plates with 3 wells for each group prepared. After $12 \mathrm{~h}$, when all the cells had attached, the exact number of cells seeded in each well was calculated visually with an inverted microscope. At the end of a two-week culturing, the relative cell number was determined using Cell Counting Kit-8 (Dojindo) according to the manufacturer's protocol. Briefly, $10 \mu 1$ of CCK-8 solution was added to each well and the plate was incubated for $1 \mathrm{~h}$ at $37^{\circ} \mathrm{C}$. Cell viability was determined by measuring the absorbance at $450 \mathrm{~nm}$. The normalized absorbance $=($ absorbance of each well/exact number of cells seeded in each well) $x 100$. The percent cell viability $(\%)=$ (absorbance of ODN transfected group - blank/absorbance of control group-blank) x 100. Blank = absorbance of the well with CCK-8 and culturing medium but no cell.

Cell cycle analysis by propidium iodide (PI) staining. At $36 \mathrm{~h}$ after transfection, $1 \times 10^{5}$ Huh-7 cells in each group were collected by centrifugation at $1000 \mathrm{rpm}$ for $5 \mathrm{~min}$ and resuspended in $1 \mathrm{ml}$ of PBS. The cells were fixed by pipeting into $2.5 \mathrm{ml}$ absolute $\mathrm{EtOH}$ to a final EtOH concentration of $70 \%$, then incubating them on ice for $15 \mathrm{~min}$. After fixation, the cells were resuspended in $500 \mu 1$ PI-solution (Sigma) in PBS, containing $50 \mu \mathrm{g} / \mathrm{ml}$ PI, $0.1 \mathrm{mg} / \mathrm{ml}$ RNase A (Sigma) and $0.05 \%$ Triton X-100 (Sigma), and incubated for $30 \mathrm{~min}$ at $4{ }^{\circ} \mathrm{C}$. PI-stained cells were analyzed on the BectonDickinson FACS Calibur system using CellQuest software. The experiments were performed three times.

\section{Results}

Knock-down (KD) of CD133/prominin-1 expression in Huh-7 and U251 cells by ASODN. To compare the CD133/ prominin-1 expression before and after the CD133-KD by ASODN in two cell lines, Huh-7 and U251, both PCR and FACS analysis were performed. We found a substantial level of CD133/prominin-1 gene transcription in untreated Huh-7 cells (Fig. 1A and C), and CD133 expression on the surface of untreated Huh-7 cells was also quite high (mean of $76.33 \%$ from three separate experiments) (Fig. 2A and B). Meanwhile, we found a low CD133/prominin-1 gene expression level as well as a very low cell surface expression rate $(1.11 \%)$ even in untreated U251 cells (Figs. 1B and D, and 2C). At $36 \mathrm{~h}$ after transfection, the CD133/prominin-1 mRNA in the CD133-KD group was apparently down-regulated (Fig. 1A and $C$ ) in both cell lines, and a significant decrease in CD133 expression was also detected in Huh-7 cells (Fig. 2A and B).

To avoid the off-target effects, we used two independent ASODN sequences respectively to knock-down the CD133/ prominin-1 and prominin-2 expression, and the results were similar, here we only show the results from CD133/ prominin-1 ASODN sequence 1, and prominin-2 ASODN sequence 1 .

Colony forming assays of Huh-7 cells. The colony forming rate of each group of Huh-7 cells was evaluated two weeks 
A
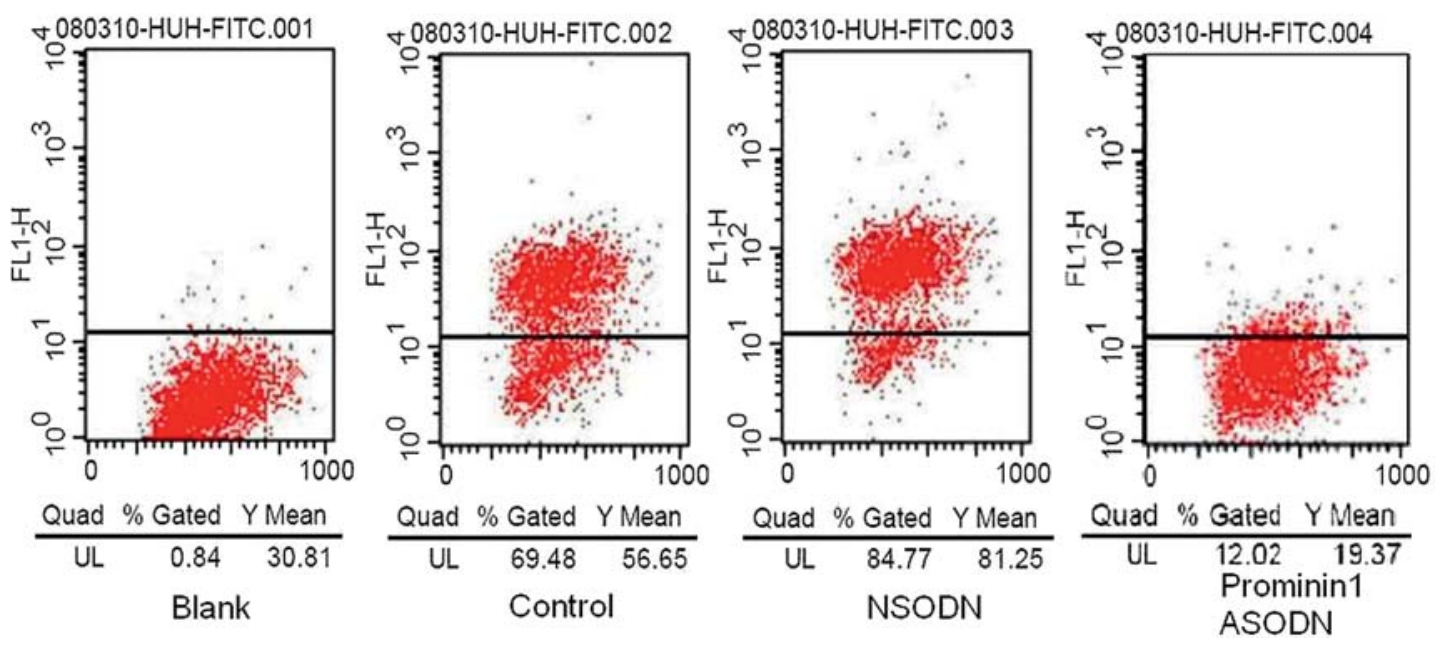

$\mathbf{B}$
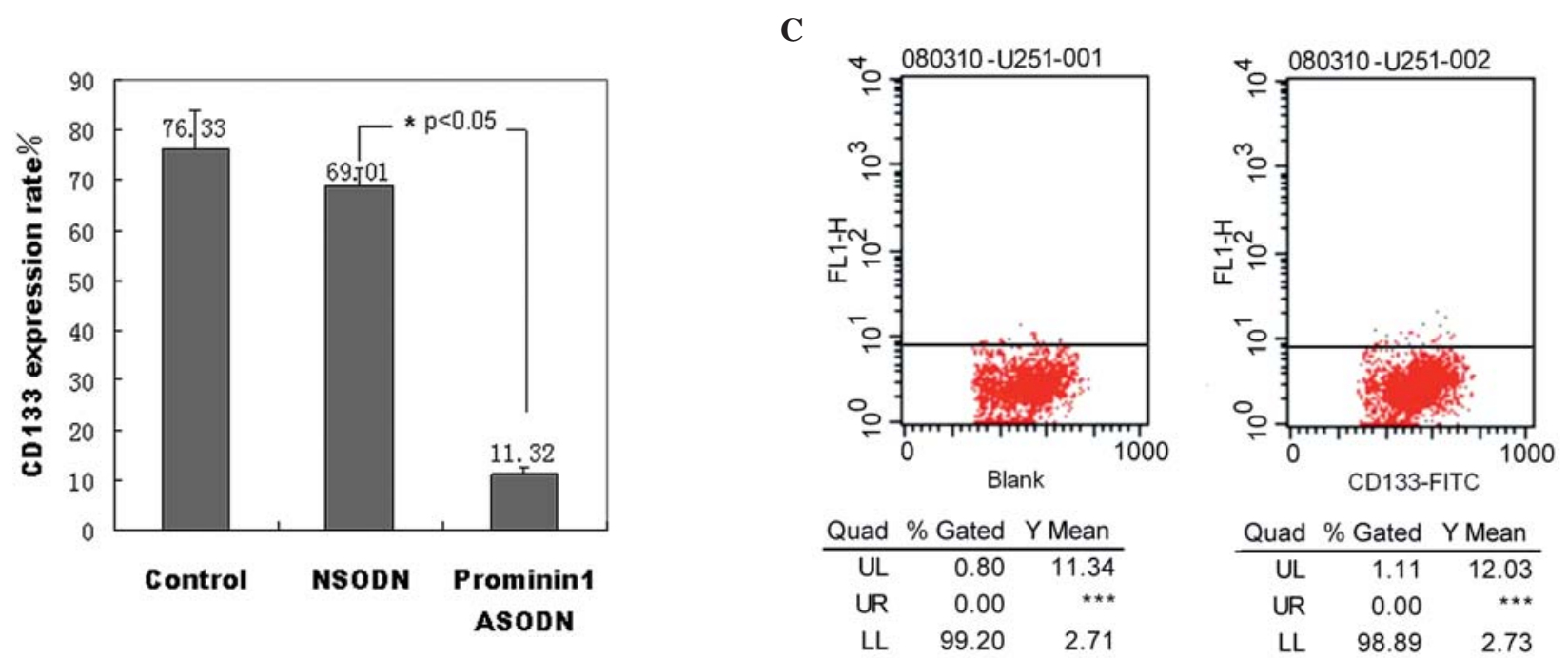

Figure 2. (A) The expression levels of CD133 in each group of Huh-7 cells $36 \mathrm{~h}$ after transfection were examined by FACS analysis. The results shown are representative of at least three independent experiments. (B) The expression rates (\%) of CD133 in each Huh-7 group are shown. The data are means \pm SD from three independent experiments. ${ }^{*}$ p $<0.05$ compared with NSODN group. (C) The expression level of CD133 in untreated U251 cells was examined by FACS analysis.

after ODN transfection. The results show that CD133/ prominin-1 ASODN caused a remarkable decrease in colony forming ability in Huh-7 cells. Colony forming abilities in both the CD133/prominin-1 ASODN groups and 1/2 prominin-1 ASDON $+1 / 2$ prominin-2 ASODN groups were significantly lower than in the NSODN groups. (Table IA and B). On the other hand, 2 weeks after transfection with prominin-2 ASODN or NSODN, there was no decrease in the colony forming rates of the cells.

Cell proliferation assay in each group of U251 cells. To evaluate the change in the in vitro proliferative activity of U251 cells caused by CD133/prominin-1 ASODN, we determined the viability of each group of U251 cells two weeks after transfection. We found that the cell viability of the CD133/prominin-1 ASODN group was remarkably lower than that of the NSODN group. Moreover, observation with an inverted microscope showed that the cells in the CD133/ prominin-1 ASODN group occupied a smaller area of the well in the plates than the other two groups and had a different appearance (Fig. 3). These findings show that the in vitro growth of U251 is inhibited by CD133/prominin-1 ASODN.

Cell cycle analysis of Huh-7 cells. In the cell cycle of Huh-7 cells, a small but significant $(\mathrm{p}<0.05)$ increase in the $S$-phase ratio and a non-significant $(0.05<\mathrm{p}<0.10)$ decrease in the G0-G1 phase ratio were detected in the CD133/prominin-1 ASODN group compared with the NSODN group. The results show that CD133/prominin-1 ASODN may alter the cellcycle distribution of Huh-7 cells (Fig. 4).

\section{Discussion}

Recent research has shown that CD133/prominin-1 often appears on the surface of cells with stem-like characteristics, including somatic and embryonic stem/progenitor cells and cancer stem cells, and also disappears together with the stemlike characteristics when the cells become differentiated $(6,17)$. Moreover, some membrane particles containing CD133/ prominin- 1 are released from these cells during differentiation 
Table I-A. Colony formation rates of the cells from five Huh-7 groups.

\begin{tabular}{|c|c|c|c|c|c|}
\hline \multirow{2}{*}{$\begin{array}{l}\text { Densities } \\
\text { (Cells seeded } \\
\text { per well) }\end{array}$} & \multicolumn{5}{|c|}{ Colony forming rates $(\%)$} \\
\hline & Control & NSODN & $\begin{array}{c}\text { Prom1 } \\
\text { ASODN }\end{array}$ & $\begin{array}{l}\text { Prom2 } \\
\text { ASODN }\end{array}$ & $\begin{array}{c}\text { Prom1 and Prom2 } \\
\text { ASODN }\end{array}$ \\
\hline 100 & $10.5 \pm 1.3$ & $9.8 \pm 1.2$ & $3.2 \pm 0.4^{\mathrm{a}}$ & $9.5+1.6^{b}$ & $4.7 \pm 0.6^{c}$ \\
\hline 50 & $10.3 \pm 1.7$ & $10.7 \pm 0.7$ & $1.9 \pm 0.3^{\mathrm{a}}$ & $9.7 \pm 1.9^{b}$ & $3.5 \pm 0.5^{\mathrm{c}}$ \\
\hline 25 & $12.3 \pm 2.6$ & $11.5 \pm 1.8$ & $5.5 \pm 0.7^{\mathrm{a}}$ & $10.9 \pm 2.3^{b}$ & $7.0 \pm 1.3^{\mathrm{c}}$ \\
\hline
\end{tabular}

Colony formation rates of the cells from five Huh-7 groups (control, $1.5 \mu \mathrm{g} /$ well NSODN, $1.5 \mu \mathrm{g} /$ well prominin- 1 ASODN, $1.5 \mu \mathrm{g} /$ well prominin-2, $0.75 \mu \mathrm{g} /$ well prominin-1 ASDON $+0.75 \mu \mathrm{g} /$ well prominin-2 ASODN) which were seeded at 25, 50 and 100 cells/well in 96well plates at $36 \mathrm{~h}$ after transfection, were determined two weeks later. The data are means \pm SD from three independent experiments. ${ }^{\mathrm{a}} \mathrm{p}<0.005,{ }^{\mathrm{b}} \mathrm{p}>0.05,{ }^{\mathrm{c}} \mathrm{p}<0.05$ compared with NSODN groups.

Table I-B. Colony formation rates of the cells from three Huh-7 groups.

\begin{tabular}{llcr}
\hline $\begin{array}{l}\text { Densities } \\
\text { (Cells seeded } \\
\text { per well) }\end{array}$ & \multicolumn{2}{c}{ Colony forming rates (\%) } \\
\cline { 2 - 3 } & Control & NSODN & Prominin-1 ASODN \\
\hline \multicolumn{1}{c}{300} & $15.8 \pm 1.2$ & $15.3 \pm 0.8$ & $6.6 \pm 0.5^{\text {a }}$ \\
\hline
\end{tabular}

Colony formation rates of the cells from three Huh-7 groups (control, NSODN and prominin-1 ASODN) seeded at 300 cells/well in 24-well plates $36 \mathrm{~h}$ after transfection, were determined two weeks later. The data are means \pm SD from three independent experiments. ${ }^{a} \mathrm{p}<0.005$ compared to the NSODN group.

A

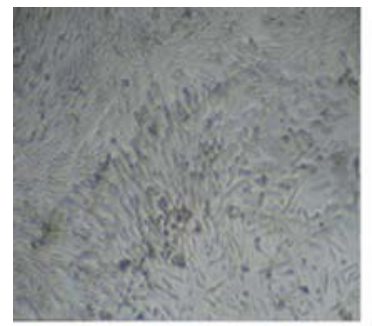

a

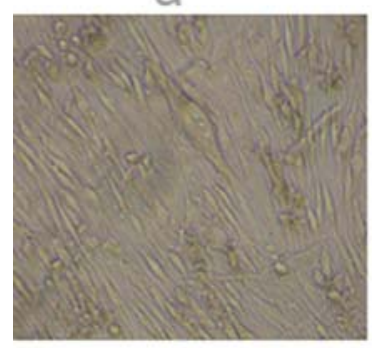

d

B

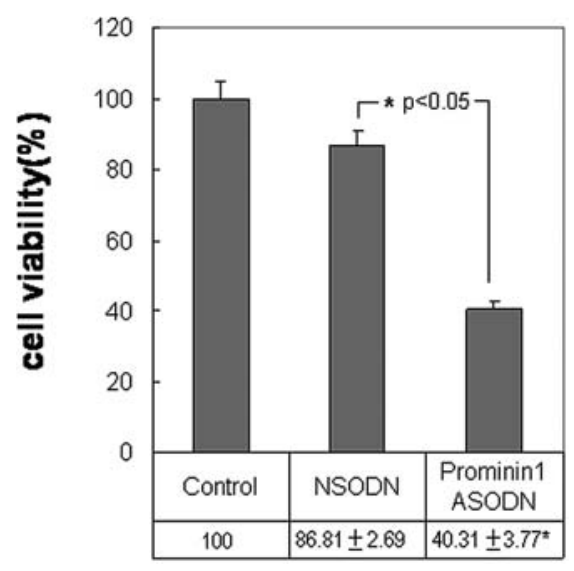

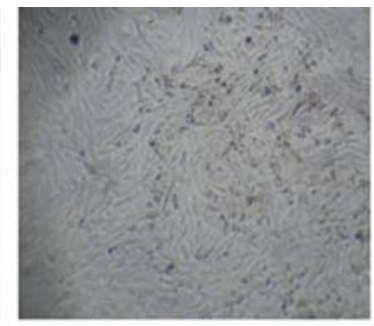

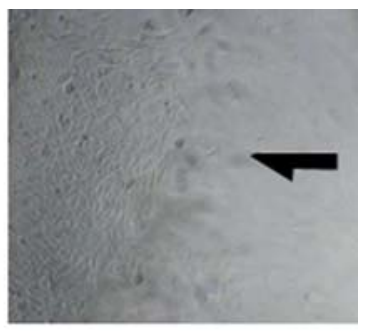

$\mathrm{b}$

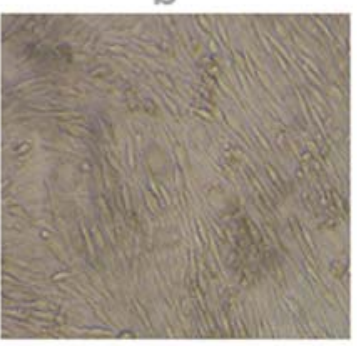

e

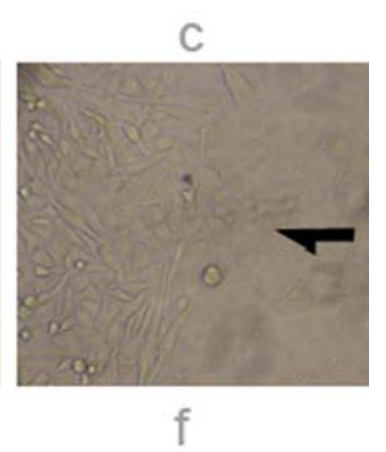

Figure 3. (A) Two weeks after transfection, each group of U251 cells was observed with an inverted microscope. Compared to the cells in the control and NSODN group, the cells in the CD133/prominin-1 ASODN group had a different appearance (f), and occupied less area in the plate, [in (c and f), large margins can be seen in the well, which are marked by the black arrow; (a and d), control group; (b and e), NSODN group; (c and f), CD133/prominin-1 ASODN group]. (B) Cell proliferation assay in each group of U251 cells. ${ }^{*} \mathrm{p}<0.05$ compared to the NSODN group.

(17). Why is CD133/prominin-1 always found on cells possessing stem-like characteristics? We hypothesized that CD133/prominin-1 plays a functional role in maintaining these stem-like characteristics and that by modulating the function 
$\mathbf{A}$
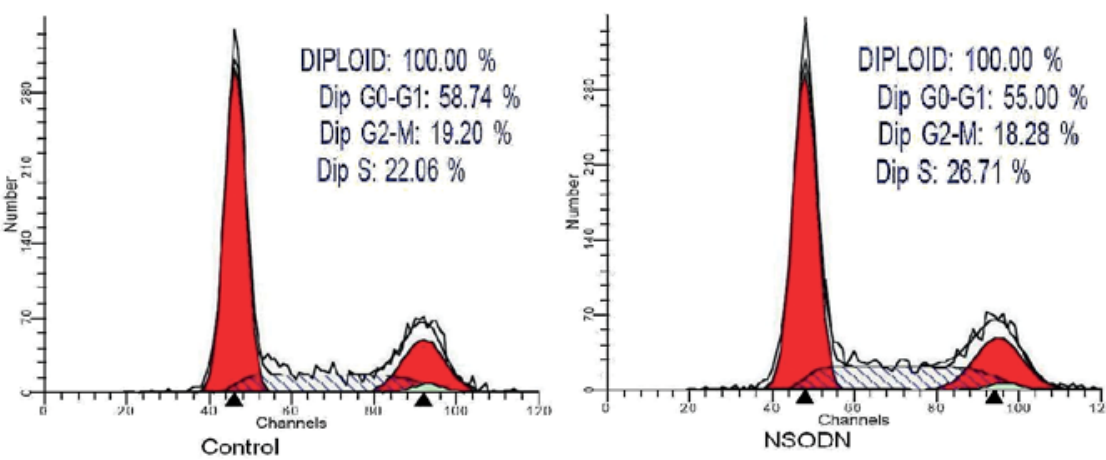

B

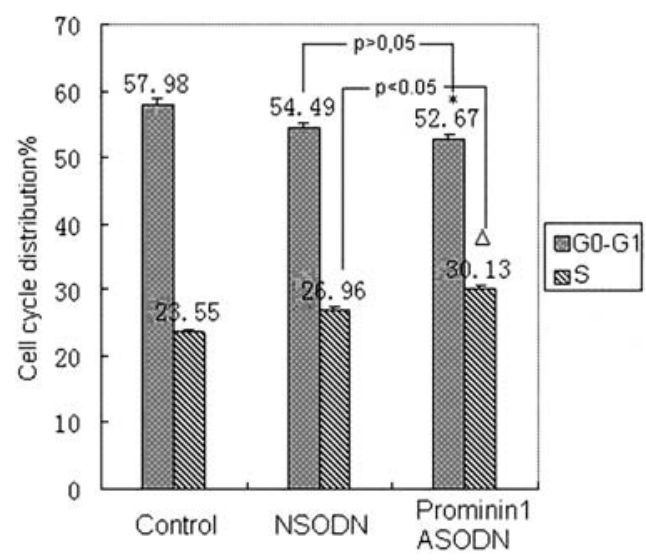

or expression of CD133/prominin-1 protein, the critical CSCs in a tumor will be changed and in consequence the whole tumor cell population will also be affected.

A better understanding of the functional role of CD133/ prominin-1 in these tumors may potentially revolutionize the cancer treatment. We investigated whether the expression level of CD133/prominin-1 can affect the in vitro growth of two different cancer cell lines, Huh-7 (high CD133 expression) and U251 (low CD133 expression), both of which have been shown to contain CD133+ CSCs $(15,19)$. We also investigated whether prominin-2, another protein in the same family, has a similar function to prominin-1.

In our study, a significant loss of CD133/prominin-1 mRNA occurred in CD133/prominin-1 ASODN-treated cells that was not seen in treatment with NSODN. The cell surface expression of CD133 was also significantly decreased after 36 h CD133/prominin-1 ASODN transfection. We showed that the expression of CD133/prominin-1 was successfully downregulated by ASODN.

The results also showed that CD133/prominin-1 ASODN caused a statistically significant reduction of cell viability in U251 cells $(\mathrm{p}<0.005)$, and a remarkable decrease of colony forming efficiency in Huh-7 cells $(p<0.005)$. These results suggested that CD133 plays an important functional role in the growth of these tumor cells, possibly by affecting the CD $133^{+}$CSCs among them.

In the cell cycle analysis, a small but significant increase in $\mathrm{S}$-phase ratio $(\mathrm{p}<0.05)$ and a non-significant decrease in G0-G1 phase ratio $(0.05<\mathrm{p}<0.10)$ were detected in the CD133/ prominin-1 ASODN group of Huh-7 cells. A reasonable
Figure 4. (A) Thirty-six hours after transfection, the cell cycle distribution of each group of Huh-7 cells was assessed by FACS. (B) The ratio of S phase and G0-G1 phase in the cell cycle in each group of Huh-7 cells was calculated. The data are means \pm SD from three independent experiments. Compared with NSODN group, a small but significant increase of S phase ratio $\left({ }^{\Delta} \mathrm{p}<0.05\right)$ and a non-significant decrease of G0-G1 phase ratio $\left({ }^{*} \mathrm{p}>0.05\right)$ was detected in the CD133/prominin-1 ASODN group.

explanation is based on the total amount of the G1 phase cells and S phase cells, the population of G1 cells is larger, S is smaller. Our result could indicate that, by controlling the expression level of CD133, we may move the cells out from their quiescent phase into their proliferating phase. This could be meaningful for therapy, but further investigation is required before drawing a conclusion.

Finally, the results of prominin-2 ASODN transfection were similar to the effects of NSODN, and did not induce any significant response after transfection in our experiment ( $p>0.05)$. Thus it appears that prominin-2 does not have the same function as prominin-1 in these tumors.

Taken together, our results demonstrate that CD133 expression appears to be a significant part of tumor growth and progression and suggest that down-regulating this expression could be used as an anticancer treatment.

\section{Acknowledgements}

The research is supported by grants from the National Natural Science Foundation of China (No.30872942), and from Natural Science Foundation of Hubei Province (No.2008CDB393). The authors thank Weidong Zhang, PhD at University of South Florida, St. Petersburg, USA, for carefully reviewing the manuscript and making valuable suggestions; Professor Juan Tao at Union Hospital, Wuhan, China, for providing us with three melanoma cell lines for pre-testing; and Mr Gary Hellermann for carefully reviewing the manuscript.

\section{References}

1. Neuzil J, Stantic M, Zobalova R, et al: Tumour-initiating cells vs. cancer 'stem' cells and CD133: what's in the name? Biochem Biophys Res Commun 355: 855-859, 2007.

2. Clarke MF and Fuller M: Stem cells and cancer: two faces of eve. Cell 124: 1111-1115, 2006.

3. Bao S, Wu Q, McLendon RE, et al: Glioma stem cells promote radioresistance by preferential activation of the DNA damage response. Nature 444: 756-760, 2006 
4. Liu GT, Yuan XP, Zeng ZH, et al: Analysis of gene expression and chemoresistance of $\mathrm{CD}_{133^{+}}$cancer stem cells in glioblastoma. Molecular Cancer 5: 67, 2006.

5. Jones RJ and Matsui W: Cancer stem cells: from bench to bedside. Biol Blood Marrow Transplant 13 (Suppl. 1): S47-S52, 2007.

6. Kania G, Corbeil D, Fuchs J, et al: Somatic stem cell marker prominin-1/CD133 is expressed in embryonic stem cell-derived progenitors. Stem Cells 6: 791-804, 2005.

7. Miraglia S, Godfrey W, Yin AH, et al: A novel fivetransmembrane hematopoietic stem cell antigen: isolation, characterization, and molecular cloning. Blood 90: 5013-5021, 1997.

8. Corbeil D, Röper K, Fargeas CA, et al: Prominin: a story of cholesterol, plasma membrane protrusions and human pathology. Traffic 2: 82-91, 2001

9. Florek M, Bauer N, Janich P, et al: Prominin-2 is a cholesterolbinding protein associated with apical and basolateral plasmalemmal protrusions in polarized epithelial cells and released into urine. Cell Tissue Res 328: 31-47, 2007.

10. Singh SK, Hawkins C, Clarke ID, et al: Identification of human brain tumour initiating cells. Nature 432: 396-401, 2004.

11. Taylor MD, Poppleton H, Fuller C, et al: Radial glia cells are candidate stem cells of ependymoma. Cancer Cell 8: 323-335, 2005.

12. Collins A, Hyde K, Berry P, et al: $\alpha 2 \beta 1 \mathrm{HI} / \mathrm{CD} 133^{+}$prostate cancer stem cells from human tumors are highly tumorigenic in vivo. Eur Urol (Suppl) 5: 790, 2006.
13. Monzani E, Facchetti F, Galmozzi E, et al: Melanoma contains CD133 and ABCG2 positive cells with enhanced tumourigenic potential. Eur J Cancer 43: 935-946, 2007.

14. O'Brien CA, Pollett A, Gallinger S, et al: A human colon cancer cell capable of initiating tumour growth in immunodeficient mice. Nature 445: 106-110, 2007.

15. Suetsugu A, Nagaki M, Aoki $\mathrm{H}$, et al: Characterization of $\mathrm{CD} 133^{+}$hepatocellular carcinoma cells as cancer stem/ progenitor cells. Biochem Biophys Res Commun 351: 820-824, 2006.

16. Ma S, Chan KW, Hu L, et al: Identification and characterization of tumorigenic liver cancer stem/progenitor cells. Gastroenterology 132: 2542-2556, 2007.

17. Marzesco AM, Janich P, Wilsch-Bräuninger M, et al: Release of extracellular membrane particles carrying the stem cell marker prominin-1 (CD133) from neural progenitors and other epithelial cells. J Cell Sci 118: 2849-2858, 2005.

18. Majka M, Ratajczak J, Machalinski B, et al: Expression, regulation and function of $\mathrm{AC} 133$, a putative cell surface marker of primitive human haematopoietic cells. Folia Histochem Cytobiol 38: 53-63, 2000.

19. Wang B, Yang H, Yin C L, et al: Isolation, culture and identification of brain cancer stem cells from malignant glioma cell line U251 in vitro. Chinese J Clin Neurosci 15: 638-642, 2007. 